\title{
Evaluation of Wound Healing Activity of Aerial Parts of Ocimum Basilicum Linn and Bark of Ficus Benghalensis Linn and Their Polyherbal Formulation in Wound Healing Models
}

\author{
*Gaurav Dubey ${ }^{1}$, Satkar Prasad ${ }^{2}$, Sailesh Kumar Ghatuary ${ }^{3}$, Anil Sarathe ${ }^{4}$, \\ Kalpana Prajapati ${ }^{5}$, Reena Sheride ${ }^{6}$. \\ ${ }^{I}$ (Dept. of Pharmachemistry, RKDF School of Pharmaceutical Science. Bhopal, India) \\ ${ }^{2}$ (Dept. of Pharmaceutics, RKDF School of Pharmaceutical Science. Bhopal, India) \\ ${ }_{3}^{3}$ (Dept. of Pharmacology, RKDF School of Pharmaceutical Science. Bhopal, India) \\ Corresponding Author: Gaurav Dubey
}

\begin{abstract}
A wound is break in the skin. Wound are usually caused by cuts or scalps, symptoms at wound or injury include swelling, stiffness, tenderness, discoloration skin tightness, itching and scar formation, two types of tissue injury: Wound healing is a complex dynamic process. The main objective of this investigation is to evaluate wound healing activity of aerial part of Ocimum basilicum Linn and bark of Ficus benghalensis Linn and their polyherbal formulation in wound healing models. Various wound healing models like Excision, Incision, Dead space wound models were evaluated on the parameters like wound contraction, Epithelisation time, tensile strength, wet and dry granuloma weight and hydroxiproline estimation. The main objective of this investigation is to develop a product, which may give a wound healing property, and enhance wound healing process like increase the collagen synthesis, fibroblast proliferation, angiogenesis and epithelization, because products which are available in market are either antiseptic or antimicrobial.
\end{abstract}

Keywords: Epithelisation, Excision, Incision, Tensile strength, Wound.

\section{Introduction}

A wound is break in the skin (the outer layer of the skin is called the epidermis). Wound are usually caused by cuts or scalps, symptoms at wound or injury include swelling, stiffness, tenderness, discoloration skin tightness, scabbing, itching and scar formation, two types of tissue injury: The process by which tissue repair takes places is called as wound healing and is comprised of a continuous sequence of inflammation and repair, in which epithelial, endothelial, inflammatory cells, platelets and fibroblasts briefly come together outside their normal domains and interact to restore resemblances of their used discipline and having done so as to resume their normal function. Wounds are major case of physical disabilities [1]. A wound which is disturbed state of tissue caused byphysical, chemical, microbial (or) immunological insults(or) typically associated with loss function. According to the wound healing society wounds are physical injuries that results in an opening (or) break of the skin that cause disturbance in the normal skin anatomy and function [2]. Wound healing is an interaction of complex cascade of cellular and bio chemical actions healing to the restoration of structural and functional integrity with regain of strength of injured tissues. Involves continuous cell - cell interaction and cell matrix interactions that allow the process to proceed in different over lapping phases and process including inflammation, wound contraction, Re epithelialization tissue, remodeling, \& formation of granulation tissue with angiogenesis [3].Several factors delay (or) reduce the wound healing process including bacterial infection, necrotic tissue, \&interference with blood supply, lymphatic blockage \&diabetes mellitus, generally if the above factors could bealtered by any agent, an increased healing rate could be achieved [4]. Many Ayurvedic plants have a very important role in the process of wound healing. Plants are more potent healers because they promote the repair mechanisms in the natural way [5)

\section{Material And Method}

2.1 Plant material: The aerial parts of $O$. basilicum and bark of F.benghalensis were collected in the month of November to December around the Bhopal. Plants were identify and authenticated in the Department of Pharmacy, Barkatullah university, Bhopal (M.P.)The aerial parts were dried in shade and plants material was powered moderately and passed through sieve No. 40.specimen of the plants were submitted as herbarium to the department with herbarium number $4032 \mathrm{~A} / \mathrm{B}$ 
2.2 Determination of physical parameters: Physical standards are to be determined, wherever possible. These are rarely constant for crude drugs, but may help in evaluation, specifically with reference to moisture content, density, foreign organic matter, crude fiber content, ash value, extractive value etc.

2.2.1 Moisture content: The percentage of active constituents in crude drug is mentioned on air dried bases. Hence, the moisture content of the crude drugs should be determined and should also be controlled. The moisture content should be minimized in order to prevent decomposition of crude drugs either due to chemical changes or microbial contamination.

Procedure Approximately $5 \mathrm{gm}$ accurately weighed powdered sample was kept in IR moisture balance. The loss in wt. was recorded as percentage (\%) moisture with respect to air-dried sample of crude drug. ${ }^{6}$

2.2.2 Total ash value Empty Aluminium foil dish was ignited, cooled and then weighed. Approximately 2 gram of accurately weighed powdered sample was placed in the dish. The dish was placed in Muffle furnace and its temperature was maintained at around $450-500^{\circ} \mathrm{C}$. The ash was collected and weighed. The percentage of total ash was then determined. ${ }^{6}$

2.2.3 Acid insoluble ash value: The ash collected from the above procedure. The ash was transferred in to a beaker and washed with $25 \mathrm{ml}$. dilute $\mathrm{HCl}$ and then boiled, filtered this ash by ash less filter paper and residue was washed twice with water. The collected residue and filter paper taken in a empty dish and put it in to Muffle furnace and its temperature was maintained at around $450-500^{\circ} \mathrm{C}$. The ash was collected and weighed. The percentage of acid insoluble ash was then determined

2.3 Extractive values:The extracts obtained by exhausting crude drugs are indicative of approximate measures of their chemical constituents. Taking into consideration the diversity in chemical nature and properties of content of drugs, various solvents are used for determination of extractives. The solvent used for extraction should be in a position to dissolve appreciable quantities of desired substances.

2.3.1Water soluble extractive value: This method is applied to those crude drugs, which contain water soluble active constituents such as tannins, sugars, plant acids, mucilage, glycosides etc.

Procedure : Approximate 5 gram accurately weighed powdered sample was taken in a conical flask and about $100 \mathrm{ml}$. solvent (Water) was added to it. The flask was cooled and set aside for $24 \mathrm{hrs}$ with frequent shaking during first 6-8 hrs. After $24 \mathrm{hrs}$ the content was filtered. The filtrate was collected and $25 \mathrm{ml}$ filtrate was transferred to a porcelain dish. Filtrate was evaporated to dryness on a water bath and complete drying was done in oven at $105^{\circ} \mathrm{C}$. then dish was weighed after cooling and value in percentage was calculated. ${ }^{6}$

2.3.2 Alcohol soluble extractive value: Alcohol is an ideal solvent for extraction of various chemicals tannins, alkaloids, resins etc. Generally, absolute alcohol (95\% v/v ethyl alcohol) is used for determination of alcohol soluble extractive.

Procedure: Approximate 5 gram accurately weighed powdered sample was taken in a conical flask and about $100 \mathrm{ml}$. Solvent (Ethanol)was added to it. The flask was cooled and set aside for $24 \mathrm{hrs}$ with frequent shaking during first 6-8 hrs. After $24 \mathrm{hrs}$ the content was filtered. The filtrate was collected and $25 \mathrm{ml}$ filtrate was transferred to a porcelain dish. Filtrate was evaporated to dryness on a water bath and complete drying was done in oven at $105^{\circ} \mathrm{C}$. the dish was weighed after cooling and value in percentage was calculated ${ }^{6}$

2.4 Extraction: $O$. basilicum Linn was extracted by maceration process using hydroalcoholic solvent and $F$. benghalensis was extracted by methanol using soxhlet apperatus. After each extraction tests were performed to see whether the drug had been completely exhausted or not. The completion of extraction was confirmed by evaporating a few drops of the extract. The powdered crude drugs $(100 \mathrm{gm}$ each) were extracted with ts on the watch glass and ensuring that no residue remained after evaporating the solvent. The liquid extracts were collected in a tared conical flask. The solvent was removed by distillation. The last traces of solvent being removed under vacuum and finally dried extracts of each plant were obtained.

2.5: Formulation preparation ${ }^{7}$

2.5.1 Formulation of ointment: Ointment of test drug extracts was prepared by using the formula given below. Ten percent ointment was prepared.

Table:1: Composition of Simple ointment base (100 gm)

\begin{tabular}{|c|l|c|}
\hline S.No. & Constituents & Quantity \\
\hline 1. & Polyethylene Glycol 400 & $40 \mathrm{gm}$ \\
2. & Polyethylene Glycol 600 & $60 \mathrm{gm}$ \\
\hline
\end{tabular}

2.5.2 Formulation of suspension: Suspension of test drug extracts was prepared by mixing 2 gm of drug with $20 \mathrm{ml}$ of Tragacanth mucilage. Mucilage was prepared by using formula given below. In which purified water added to make it $100 \mathrm{gm}$. 
Table:2 : Composition of Tragacanth mucilage (100 gm)

\begin{tabular}{|c|c|c|}
\hline S.No. & Constituents & Quantity \\
\hline 1. & Glycerin & $18 \mathrm{gm}$ \\
\hline 2. & Purified water & $75 \mathrm{ml}$ \\
\hline 3. & Tragacanth & $2 \mathrm{gm}$ \\
\hline 4. & Benzoic acid & $0.2 \mathrm{gm}$ \\
\hline
\end{tabular}

\section{6: Wound healing activity}

2.6.1: Selection of model: Excision, Incision and Dead space wound model, using Albino rats was selected for assessing the wound healing activity. This model was employed to study the rate of wound contraction, time required for full epithelization, tensile strength, granuloma weight and hydroxyproline estimation. These parameters were selected because of easy availability of Albino rat and simplicity in handling them.

2.6.2 Selection and procurement of animals: After taking permission for animal studies from Institutional Animals Ethics Committee (, albino rats were procured and rats of either sex weighing 150-200 gm were selected, maintained at $24-28^{\circ} \mathrm{C}$, housed individually with free access to food and water. The animals were left for $48 \mathrm{hr}$. to acclimatize to the animal room conditions. They were fed with standard diet.To perform the experiment, the rats were divided into four groups $(n=6)$.

Group I: Kept as CONTROL group which received simple vehicle.

Group II: Kept as TEST I which received extract of ariel part of $O$. basilicum formulation.

Group III: Kept as TEST II which received extract of bark of $F$. benghalensis formulation.

Group IV: Kept as TEST III which received polyherbal formulation of both extracts.

2.6.3 Statistical Analysis: The results were analyzed by one-way ANOVA and a P-value less than 0.01 was considered significant. ${ }^{8}$

\subsubsection{Excision wound model}

In the excision wound model, rats were depilated by removing hairs at the dorsal thoracic region before wounding. Rats were anaesthetized by diethyl ether prior to excision. Circular wound of about $2.5 \mathrm{~cm}$ diameter was made on depilated dorsal thoracic region of rats under aseptic conditions and were observed throughout the study. The areas of the wounds were measured (in $\mathrm{mm}^{2}$ ) immediately by placing a transparent polythene graph paper over the wound and then tracing the area of the wound on it (Approx. area $500 \mathrm{~mm}^{2}$ ). This was taken as the initial wound area reading.

The rats are categorized into four groups $(\mathrm{n}=6)$. The animal of group I treated as control and only ointment base applied topically. The animal of group II, III and IV treated as TEST I, TEST II, TEST III and ointment of $O$. basilicum, $F$. benghalensis and polyherbal applied topically, respectively. All the samples were applied once daily for 16 days, starting from the day of wounding. The observations of percentage wound closure were made on 4th, 8th, 12th and 16th, post wounding days. The wound area of each animal was measured by using tracing paper method. The percentage of wound contraction was calculated from the days of measurements of wound area. ${ }^{9}$

2.6.4.1 Wound Contraction: The wound contraction was calculated as percentage reduction in wound area with respect to initial wound area while the epithelization time was noted as the number of days after wounding required for scar to fall off leaving no raw wound behind.

\subsubsection{Incision wound model}

In the incision wound model, rats depilated by removing hairs at the dorsal thoracic region before wounding. Rats were anaesthetized by diethyl ether prior to incision. Six centimeter long paravertebral incisions were made through full thickness of skin on either side of vertebral column of the rat. The wounds were closed with interrupted sutures of one centimeter apart.

The rats are categorized into four groups $(\mathrm{n}=6)$. The animal of group I treated as control and only ointment base applied topically. The animal of group II, III and IV treated as TEST I, TEST II, TEST III and ointment of $O$. basilicum, $F$. benghalensis and polyherbal applied topically, respectively. All the samples were applied once daily for 16 days, starting from the day of wounding. The sutures were removed on $8^{\text {th }}$ post wounding day. The tensile strength of wounds was measured on $10^{\text {th }}$ day following continuous water flow technique. ${ }^{09}$

\subsubsection{Tensile strength in Incision wound model}

The tensile strength was calculated in incision wound model. On $10^{\text {th }}$ day the rats were again anesthetized and each rat is placed on a stack of paper towel on the middle of the board. The amount of the towel could be adjusted in such a way so that the wound is on the same level of tips of the arms. The clamps are then carefully clamped on the skin of the opposite side of the skin of wound at a distance of $0.5 \mathrm{~cm}$ away from the wound. The longer pieces of the fishing line are placed on the pulley and finally to the polyethylene bottle and the position of the board is adjusted so that the bottle receive a rapid and constant rate of water from the 
large reservoir, until the wound began to open. The amount of water in polyethylene bag is weighted and consider as tensile strength of the wound.

\subsubsection{Dead space wound model}

In this model, a dead space wound were created by subcutaneous implantation of sterilized cylindrical grass pith $(2.5 \mathrm{~cm} \times 0.3 \mathrm{~cm})$, under light ether anesthesia, on either side of the dorsal paravertebral surface of rat. The rats are categorized into four groups $(\mathrm{n}=6)$. The animal of group I treated as control and received one $\mathrm{ml}$ of $2 \%$ tragacanth solution, orally. The animal of group II, III and IV treated as TEST I, TEST II and TEST III and received one $\mathrm{ml}$ of oral suspension of $O$. basilicum, $F$. benghalensis and polyherbal, respectively, in the dose of $500 \mathrm{mg} / \mathrm{kg}$ body weight. All the samples were given once daily for 10 days, starting from the day of wounding. The granulation tissue formed on the grass piths were excised on $10^{\text {th }}$ post wounding day. The dry weight of the granulation tissues was measured and hydroxyproline estimated. ${ }^{09}$

\subsubsection{Dry granuloma weight}

The granuloma was collected from grass pith at $10^{\text {th }}$ day from dead space wound model. The granuloma was dried at $60^{\circ} \mathrm{C}$ for three hour and weighted.

\subsubsection{Hydroxyproline estimation in Dead space model}

Procedures: The granuloma tissue formed was collected for the estimation of hydroxyproline. Calculated quantities of tissue sample were immersed in $2 \mathrm{ml}$ of $6 \mathrm{M}-\mathrm{HCl}$, and the tubes were sealed without evacuation. Hydrolysis was done for $3 \mathrm{hr}$ at $105^{\circ} \mathrm{C}$. After hydrolysis of tissue, $50 \mu \mathrm{l}$ of sample was taken and $0.4 \mathrm{ml}$ isopropanol was mixed to it. Then, $0.2 \mathrm{ml}$ of solution A was mixed and incubated at room temperature for 5 min. After incubation, $2.5 \mathrm{ml}$ of solution B was mixed and incubated at $58^{\circ} \mathrm{C}$ for $25 \mathrm{~min}$. Then this mixture was cooled in tap water and absorbance was taken at $558 \mathrm{~nm}$ within $30 \mathrm{~min}$. The quantity of hydroxyproline was calculated with the help of standard curve.

\section{Result And Discussion}

Physical parameters e.g. moisture content, ash values and extractive values of ariel part of $O$. basilicum and bark of $F$. benghalensis were determined and the values revealed the authentication of plants on comparison with their respective standards. The experimental values are shown in Table 03 and 04 . Ash value determination is a very important tool to access the quality of herbal raw material since higher ash value is an indication of adulteration and or improper processing of raw material. The percentage variation of the weight of ash in certain drugs from sample to sample is very small and any marked difference indicates a change in quality. Total ash is designed to determine the amount of material that remains after incineration. Total ash can be classified as physiological which is derived from plant itself and non-physiological ash which derives from extraneous matter like sand and soil. Acid insoluble ash is the residue obtained after boiling the total ash with hydrochloric acid and incinerating the washed insoluble matter left on the filter paper Moisture is an unavoidable component of the crude drugs, and it must be reduced as much as possible. Drying of the crude drug will help in their preservation, it will stop enzymatic or hydrolytic reactions which might alter the nature of the phytoconstituents of the drugs;

Table No. 03: Physicochemical parameters

\begin{tabular}{|c|l|c|c|}
\hline S.No. & Parameters & O. basilicum (in \%) & F. benghalensis (in \%) \\
\hline 1. & Moisture Content & $5.70 \%$ & $4.90 \%$ \\
\hline 2. & Total Ash & $8.5 \%$ & $12.5 \%$ \\
\hline 3. & Acid Insoluble Ash & $6.0 \%$ & $2.0 \%$ \\
\hline
\end{tabular}

Extractive value determinations tell us the amount of phytoconstituents in a given amount of medicinal plant material when extracted with a particular solvent. Under a given sent of conditions theses values varies within a narrow limit and hence can be set as an in-house standard for routinely used drugs. These values can also tell us about the adulteration of crude drug with already exhausted drug as it will yield low extractive values. The results of alcohol soluble and water soluble extractive values are shown in Table No 04

Table No. 04: Extractive Values

\begin{tabular}{|c|l|c|c|}
\hline S.No. & Extractive values & O. basilicum (in \%) & F. benghalensis (in \%) \\
\hline 1. & Alcohol Soluble & $33.81 \%$ & $4.85 \%$ \\
\hline 2. & Water Soluble & $22.0 \%$ & $10.5 \%$ \\
\hline
\end{tabular}

The studies on Excision wound healing model reveals that all the three groups showed decreased wound area from day to day. There was noticeable homogeneity in the wound contraction observed for animals 
in the experimental groups compared with the control group. However, on $16^{\text {th }}$ post wounding day, animals of control group showed $88.17 \%$ of healing (which may be due to self immunity of the animals) where as $O$. basilicum extract's ointment treated group (TEST I) showed $97.97 \%$ healing. On the other hand, $F$. benghalensis extract's ointment treated group (TEST II) showed $95.79 \%$ of wound healing and the polyherbal treated group showed $88.44 \%$ wound healing All readings are found to be statistically significant and comparable with control (Table 0.5)

Table No.0.5: Percentage wound contraction in excision Wound Model

\begin{tabular}{|c|c|c|c|c|c|}
\hline \multicolumn{7}{|c|}{ Area of wound closure (sq mm \pm S.E.M) } \\
\hline Groups & $\mathbf{4}^{\text {th }}$ day & $\mathbf{8}^{\text {th }}$ day & $\mathbf{1 2}^{\text {th }}$ day & $\mathbf{1 6}^{\text {th }}$ day & $\begin{array}{c}\text { Epithelization } \\
\text { period (Days) }\end{array}$ \\
\hline I & $\begin{array}{c}224.75 \pm 0.63 \\
(55.04 \%)\end{array}$ & $\begin{array}{c}160.16 \pm 0.63 \\
(67.95 \%)\end{array}$ & $\begin{array}{c}101.51 \pm 0.95 \\
(79.69 \%)\end{array}$ & $\begin{array}{c}59.13 \pm 0.86 \\
(88.17 \%)\end{array}$ & 22 \\
\hline CONTROL) & $163.93 \pm 0.38^{*}$ \\
II & $\begin{array}{c}68.70 \pm 0.33^{*} \\
(86.25 \%)\end{array}$ & $\begin{array}{c}19.95 \pm 0.79^{*} \\
(96.0 \%)\end{array}$ & $\begin{array}{c}10.12 \pm 0.68^{*} \\
(97.97 \%)\end{array}$ & 18 \\
\hline III & $\begin{array}{c}207.62 \pm 0.44^{*} \\
(58.47 \%)\end{array}$ & $\begin{array}{c}111.14 \pm 2.14^{*} \\
(77.77 \%)\end{array}$ & $\begin{array}{c}51.87 \pm 0.37^{*} \\
(89.62 \%)\end{array}$ & $\begin{array}{c}21.43 \pm 0.50^{*} \\
(95.79 \%)\end{array}$ & 20 \\
\hline (TEST-II) & $\begin{array}{c}208.18 \pm 1.07^{*} \\
\text { IV }\end{array}$ & $\begin{array}{c}122.18 \pm 1.10^{*} \\
(75.56 \%)\end{array}$ & $\begin{array}{c}61.78 \pm 1.08^{*} \\
(87.64 \%)\end{array}$ & $\begin{array}{c}57.91 \pm 0.75^{*} \\
(88.44 \%)\end{array}$ & 21 \\
(TEST-III) & $(58.36 \%)$ & & &
\end{tabular}

\# Initial wound area approx. $500 \mathrm{sq} \mathrm{mm}$

$\approx \mathrm{n}=6$ animals in each groups.

$\neq$ Result expressed as Mean Area \pm S.E.M.

* $\mathrm{P} \leq 0.01$ indicates significant when compared with control.

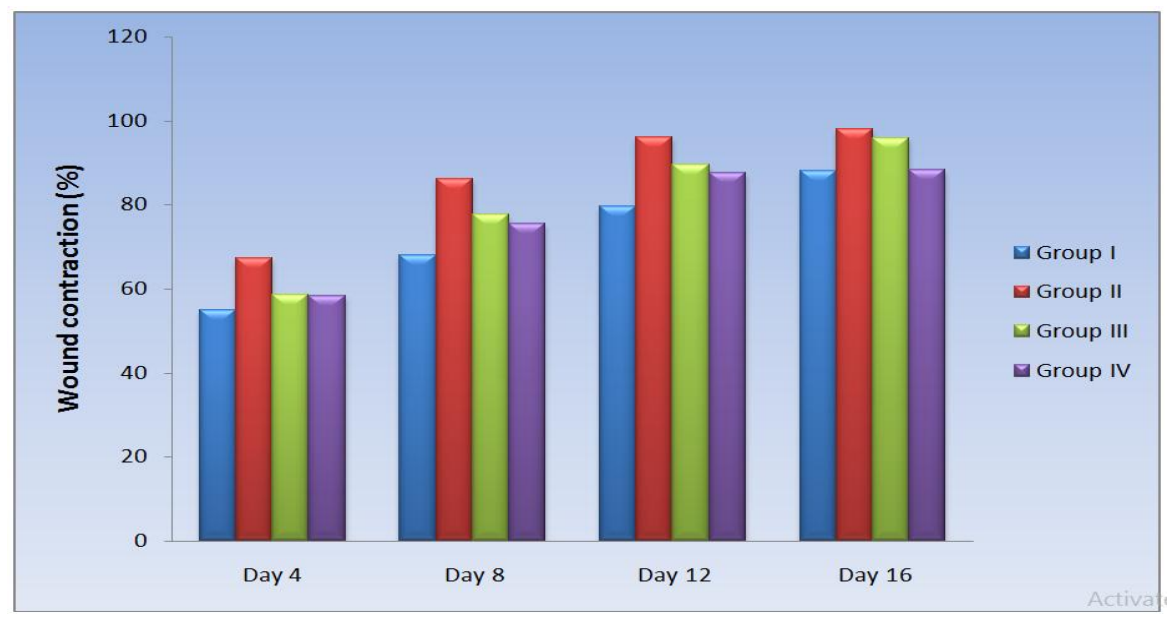

Graph01: Percentage wound contraction

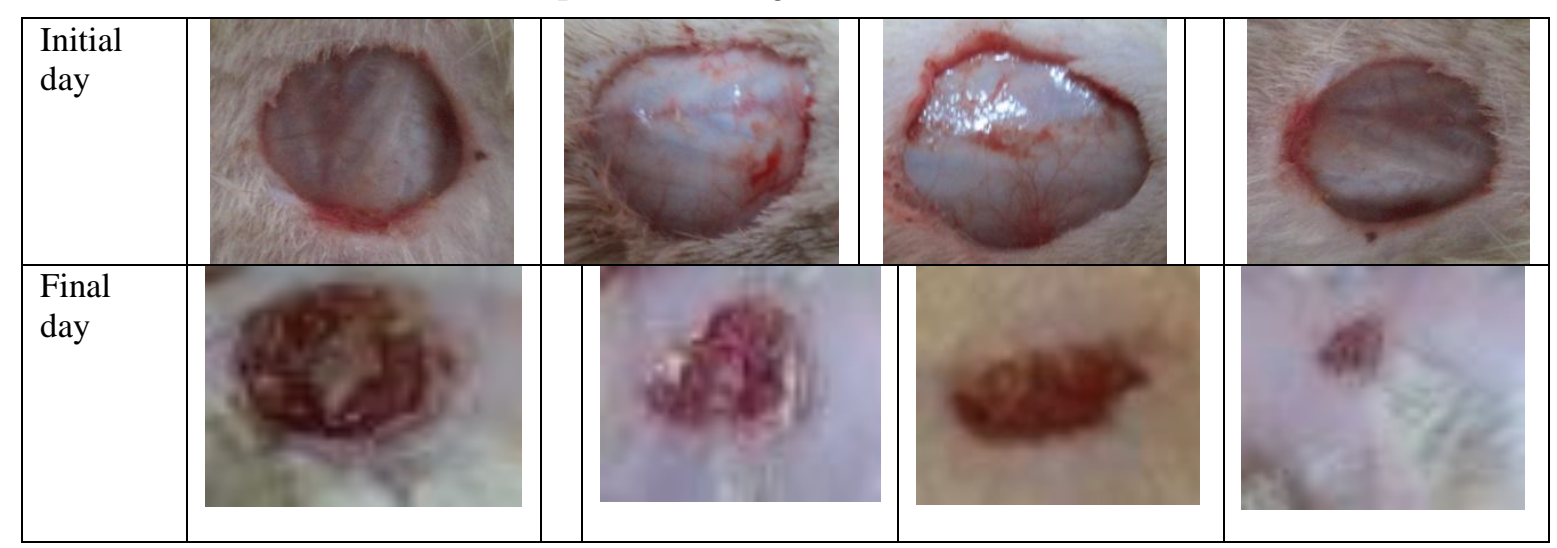

Fig01: Excision wound model

In Incision wound model on $10^{\text {th }}$ post wound day tensile strength were measured which shows that Test I drug formulation shows higher tensile strength as compare to other groups.. $F$. benghalensis and polyherbal extract's ointment treated group showed better tensile strength when compare with control group which shows in Table 0.6 and Graph 02 .

Table No. 0.6 : Tensile strength in incision model

\begin{tabular}{|c|c|}
\hline Groups & Tensile strength (in Grams) \\
\hline $\begin{array}{c}\text { I } \\
\text { (CONTROL) }\end{array}$ & $233.16 \pm 3.31$ \\
\hline II & \\
\hline
\end{tabular}




\begin{tabular}{|c|c|}
\hline (TEST-I) & $350.83 \pm 2.56$ \\
\hline $\begin{array}{c}\text { III } \\
\text { (TEST-II) }\end{array}$ & $334.66 \pm 2.40$ \\
\hline $\begin{array}{c}\text { IV } \\
\text { (TEST-III) }\end{array}$ & $319.50 \pm 2.71$ \\
\hline
\end{tabular}

$\neq$ Result expressed as Mean Area \pm S.E.M.

$* \mathrm{P} \leq 0.01$ indicates significant when compared with control.

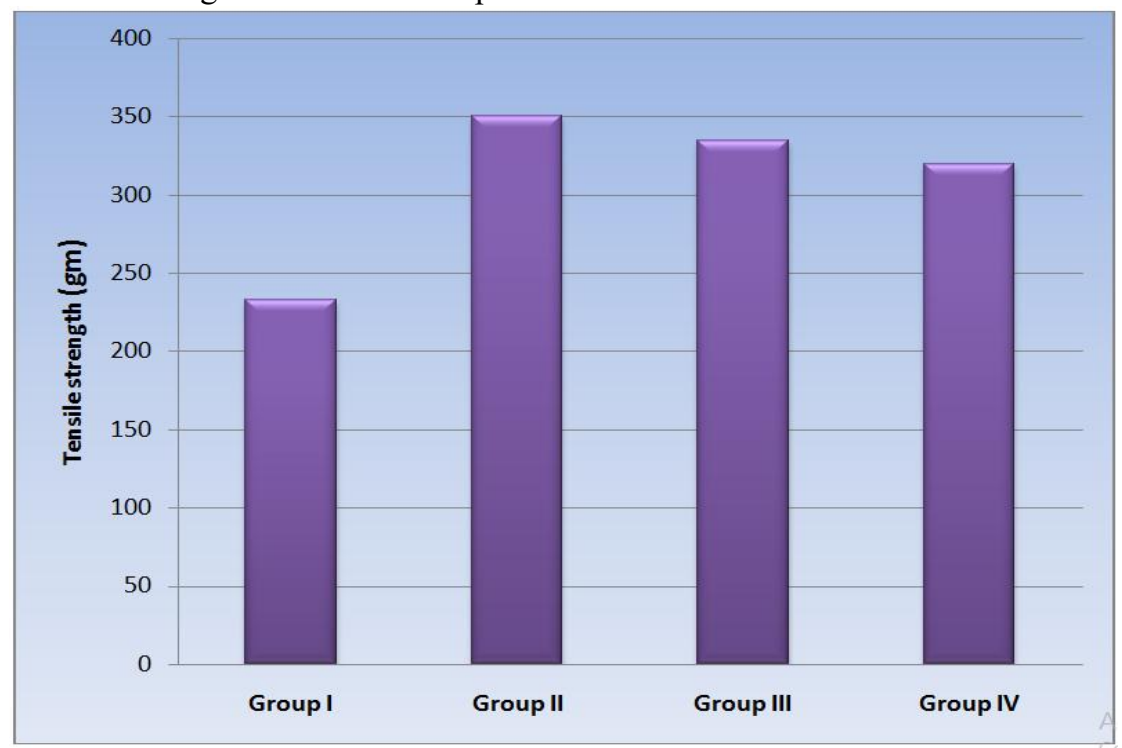

Graph02: Tensile strength in Incision wound model

The study on Dead space wound model revel that all four groups showed formation of granuloma tissue. The group which received $F$. benghalensis suspension shows higher dry granuloma weight and higher hudroxiproline which indicate that $F$. benghalensis suspension shows better result. Test I and polyherbal suspension shows good result as compare to control group which shows in Table no 07and Graph 03.

\begin{tabular}{|c|c|c|}
\hline Groups (n) & $\begin{array}{c}\text { Dry granuloma weight } \\
\text { (gm) }\end{array}$ & $\begin{array}{c}\text { Hydroxyproline } \\
\text { (mg/g of tissue) }\end{array}$ \\
\hline $\begin{array}{c}\text { I } \\
\text { (CONTROL) }\end{array}$ & $32.85 \pm 0.22$ & $17.69 \pm 0.49$ \\
\hline $\begin{array}{c}\text { II } \\
\text { (TEST-I) }\end{array}$ & $49.93 \pm 0.53$ & $22.54 \pm 0.57$ \\
\hline $\begin{array}{c}\text { III } \\
\text { (TEST-II) }\end{array}$ & $55.10 \pm 0.19$ & $26.18 \pm 0.32$ \\
\hline $\begin{array}{c}\text { I } \\
\text { (TEST-III) }\end{array}$ & $49.26 \pm 0.33$ & $21.75 \pm 0.62$ \\
\hline
\end{tabular}

Table No 0.7: Dry granuloma weight and Hydroxyproline estimation in Dead space wound healing model $\neq$ Result expressed as Mean Area \pm S.E

$* \mathrm{P} \leq 0.01$ indicates significant when compared

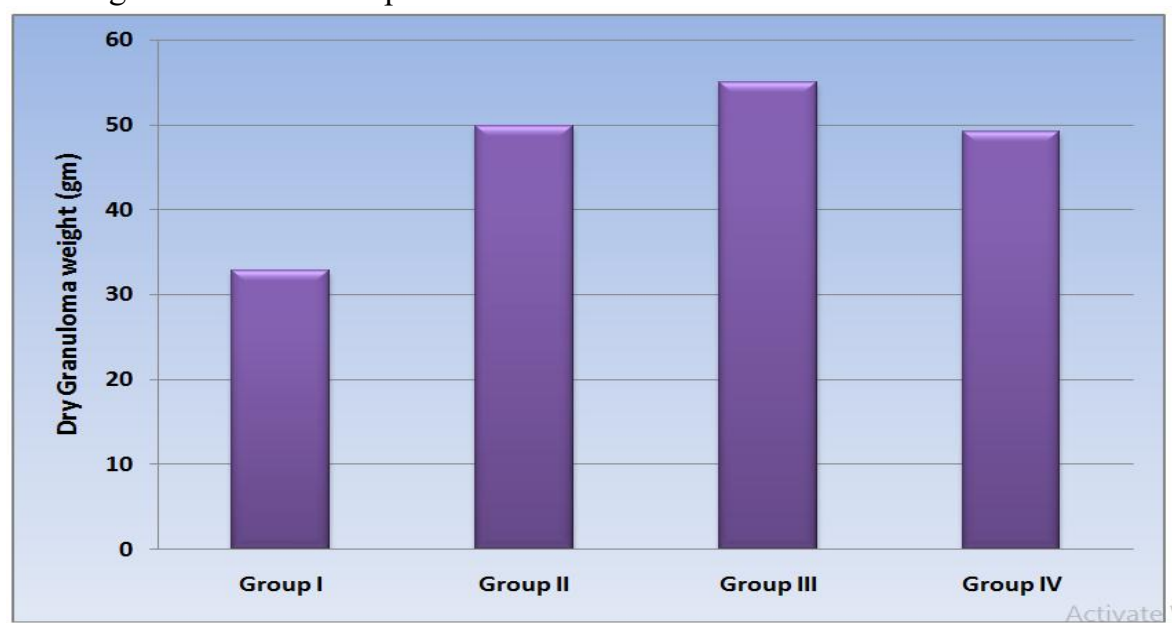

Graph03: Dry granuloma weight in dead space wound model 


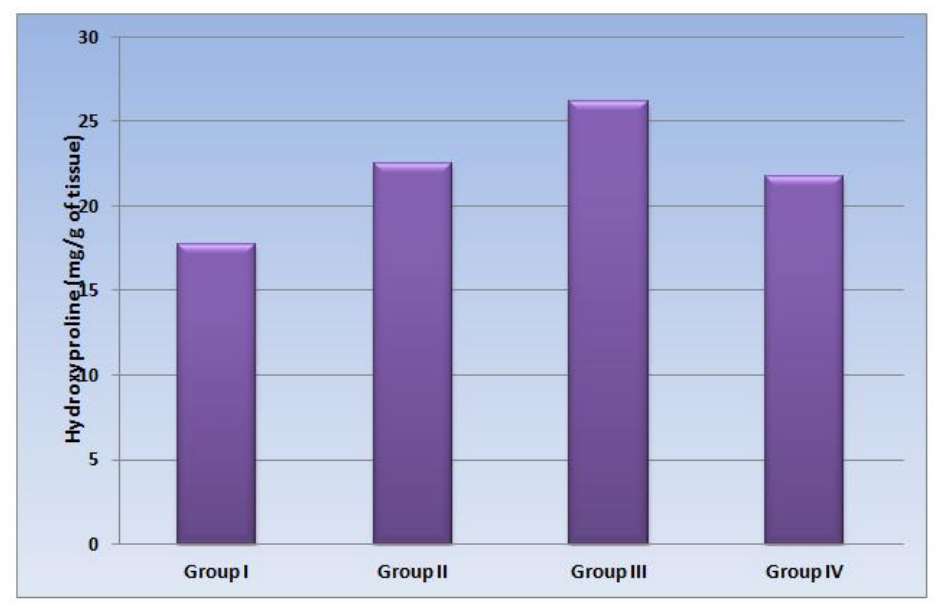

Graph04: Hydroxiproline estimation in dead space wound model

\section{Conclusion}

The phytochemical studies have clearly demonstrated that both the plants are a rich source of phenolics and flavonoids. Therefore, the presence of these compounds in the plant extracts has exhibited strong antioxidant and pharmacological activities. The activities of extracts of ocimum basilicum and Ficus benghalensis, have clearly shown that both the plants possess antioxidant and wound healing potential. On the basis of the results obtained in the present investigation, it is possible to conclude that the ointment of the extract of ariel part of $O$. basilicum and bark of $F$. benghalensis and its polyherbal formulation has significant wound healing activity. The above findings justify the wound healing properties of the $O$. basilicum and $F$. benghalensis as suggested in the traditional literatures was comparable with control.

When wound healing activity of ariel part of $O$. basilicum and bark of $F$. benghalensis and its polyherbal formulation are compared, $F$. benghalensis, shows better activity in all three wound healing models. The wound healing property of $O$. basilicum and $F$. benghalensis appears to be due to the presence of its active principles, which accelerates the healing process and confers breaking strength to the healed wound. Several phytoconstituents like flavonoids and tannins are known to promote wound healing process due to their antioxidant activities. The study reveals that $O$. basilicum, $F$. benghalensis and its polyherbal formulation treated groups possesses good wound healing properties which may be attributed to the individual or combined action of phytoconstituents like alkaloids, flavonoids and tannins present in it. Further investigations are necessary to determine the bioactive constituents present in the extracts used for studies.

\section{Acknowledments}

The authors are thankful to RKDF school of pharmaceutical science for providing helpful critique and suggestions.

\section{Reference}

[1] Baddui, Prakesh ,Nagori et al.,Role of medicinal plants inwound healing, Research Journal of medicinal plants,2011,5(4):392-40.

[2] F Strodtbeck, Physiology of wound healing, new borninfant nurse,2001 Rev.I, page 43-45.

[3] P.Martin, Wound healing - Aiming for perfect skinregeneration, science,1991 vol. 276.No: 5309, pp 75-81.

[4] P Chitra, G.B Sajithalal and G Chandrakasan, Influence Aloe Vera, on collagen turnover in healing of dermal wounds inrates, Indian journal of Exp. Biol, 1998,36: 896-901.

[5] Chitra shenoy, M.B Patil, Ravikumar, Preliminaryphytochemical investigation and wound healing activity ofAllium.Cepalin (Liliaceae). International journal of pharmacy andpharmaceutical sciences; vol.2, issue 2, July - Sep.

[6] Indian Pharmacopoeia, Vol. II, Delhi, Controller of Publication, 1996,A3,38

[7] Harborne J B, Williams C,A Phytochemical Methods, Chapman \& Hall, New York, 1983,22(6) P1520-1521

[8] Armitage P, Statistical method in medical research, Blackwell scientific publication London, 1971,217

[9] Shirwaikar A, Jahagirdar S, Udupla A L,wound healing cativity of Desmodium Triquetrum leaves, Indian $\mathrm{j}$ Pharmasci,2003,65(5),461-464

IOSR Journal of Pharmacy and Biological Sciences (IOSR-JPBS) is UGC approved Journal with S1. No. 5012, Journal no. 49063.

Gaurav Dubey. "Evaluation of Wound Healing Activity of Aerial Parts of Ocimum Basilicum Linn and Bark of Ficus Benghalensis Linn and Their Polyherbal Formulation in Wound Healing Models." IOSR Journal of Pharmacy and Biological Sciences (IOSR-JPBS) 12.4 (2017): 50-56. 